\title{
Concepciones del profesorado y del estudiantado del primer año de estudios de Psicología sobre la lectura
}

\author{
MARÍA MICAELA VILLALONGA PENNA* \\ Universidad Nacional de Tucumán - Argentina \\ Recibido el 02-08-18; primera evaluación el 19-07-19; \\ segunda evaluación el 05-08-19; tercera evaluación el \\ 08-08-19; aceptado el 28-08-19
}

\section{RESUMeN}

En este trabajo, consideramos el material de lectura del primer año de la carrera de Psicología de una universidad estatal y describimos las concepciones de los docentes y de los estudiantes en relación con esto. Para ello, entrevistamos a docentes y estudiantes ingresantes de la mencionada carrera y recolectamos el material de las diferentes asignaturas del primer año. Analizamos las entrevistas y el material de lectura a la luz de categorías que se desprenden del marco teórico y teniendo en cuenta las emergentes también. Hallamos que en el material de lectura priman los textos académicos derivados de textos científicos predominantemente expositivos. Además, encontramos diferencias entre los docentes con mayor y menor experiencia y entre los estudiantes, según su rendimiento académico, en cuanto a sus conocimientos acerca de las clases textuales.

Palabras clave: lectura, docencia, estudiantes, psicología

\section{Psychology first course teacher's and student's conceptions about reading}

\section{Abstract}

In this paper, we consider the reading material of the first year of the Psychology degree of a public university and we describe the teacher's and student's

\footnotetext{
* Licenciada en Psicología por la Universidad Nacional de Tucumán en Argentina. Magíster en Psicología Cognitiva y Aprendizaje por la Facultad Latinoamericana de Ciencias Sociales (FLACSO) en Argentina. Doctora en Ciencias de la Educación por la Universidad Nacional de Córdoba en Argentina. Becaria posdoctoral en el Instituto de Investigaciones sobre el Lenguaje y la Cultura (INVELEC) y el Consejo Nacional de Investigaciones Científicas y Técnicas (CONICET). Docente de grado y posgrado en la Facultad de Psicología de la Universidad Nacional de Tucumán (UNT). Correo electrónico: micavillalonga@yahoo.com.ar
} 
conceptions in relation to this. We interviewed teachers and incoming students of the aforementioned career and we collected material from the different subjects of the first year. We analyze interviews and reading material in light of categories that emerge from the theoretical framework and we took into account emerging ones. We find that the reading material included academic texts derived from scientific texts predominantly expository. In addition, we found differences in terms of the knowledge about textual classes between teachers with more and less experience and among students according to their academic performance.

Keywords: reading, teaching, students, psychology

\section{Concepçóes de professores e estudantes do primeiro ano de psicologia estudos sobre a leitura}

\section{Resumo}

Neste artigo, nós consideramos o material de leitura do primeiro ano do curso de Psicologia de uma universidade estadual e descrevemos as concepçóes de professores e alunos em relação a isso. Entrevistamos professores e novos alunos da carreira citada e coletamos material dos diferentes assuntos do primeiro ano. Analisamos entrevistas e material de leitura à luz de categorias que emergem do referencial teórico e levam em conta as emergentes. Verificamos que os textos acadêmicos derivados de textos científicos predominantemente expositivos predominam no material de leitura. Além disso, encontramos diferenças entre professores com mais e menos experiência e entre os alunos de acordo com o desempenho acadêmico em termos de conhecimento sobre as classes textuais.

Palavras chave: leitura, ensino, estudantes, psicologia 


\section{INTRODUCCIÓN}

La lectura, en contextos académicos, constituye un complejo proceso en el que múltiples aspectos se ven imbricados. Entre estos aspectos, se encuentran las perspectivas o concepciones acerca de la lectura y qué es lo que se lee en el marco de diferentes comunidades disciplinares (Barton, Hamilton y Ivanic, 2000; Barton y Tusting, 2005; Blommaert, Street, Turner y Scott, 2007; Cassany, 2005; Lea, 2005; Lillis y Scott, 2007). Estudios internacionales y nacionales han dado a conocer brechas o distancias entre las perspectivas y las prácticas en torno a la lectura (Carlino, 2003; Lea, 2005; Lillis y Scott, 2007) y que, en el área de las ciencias sociales, los estudiantes suelen acceder académicos derivados de textos científicos (Carlino, 2005; Fernandez y Carlino, 2013; Savio, 2015). En este sentido, la pregunta de investigación que abordamos está referida a ¿qué se lee en el primer año de la carrera de Psicología y qué declaran los alumnos y los docentes que se lee?

\section{MarCo teórico}

Como fuera señalado, desde las Alfabetizaciones Académicas y la Literacidad Crítica, se considera que la lectura en comunidades disciplinares académicas es un proceso en el que se entraman las perspectivas o concepciones acerca de la lectura y lo que se lee en las disciplinas o los géneros académicos disciplinares —entre muchos otros- (Barton, Hamilton y Ivanic, 2000; Barton y Tusting, 2005; Blommaert, Street, Turner y Scott, 2007; Cassany, 2005; Lea, 2005; Lillis y Scott, 2007). Desde ambos enfoques teóricos, se plantea la necesidad de reflexionar acerca de qué es lo que los estudiantes y docentes conciben que es leer y escribir en las disciplinas, ya que muchas veces estas concepciones pueden contraponerse y, por un lado, los docentes pueden esperar que los estudiantes se comporten como competentes lectores de géneros académicos, aunque no hayan enseńado esto y, por el otro, los estudiantes pueden esperar que los docentes les enseñen cómo abordar la lectura disciplinar - aunque esto no llegue a suceder- (Barton, Hamilton y Ivanic, 2000; Blommaert, Street, Turner y Scott, 2007; Cassany, 2005; Chanock, 2011; Lillis y Scott, 2007).

Sobre qué se lee en la universidad, Parodi (2015) entiende que los géneros académicos presentan gran diversidad, siendo que algunos son creados en el ámbito universitario y otros se importan desde el campo científico o profesional (Parodi, 2008; Bolívar y Parodi, 2015; Parodi, 2015). Además, se identifican géneros con patrones recursivos de tipo didáctico o divulgativo (por ejemplo, manuales, guías didácticas), prosas altamente especializadas e informacional- 
mente densas (por ejemplo, textos disciplinares) o aquellas que se escriben en el grado y pre-grado, pero que son fundamentales en la vida laboral científica (por ejemplo, reseñas, artículos y proyectos de investigación) (Parodi, 2008; Parodi, 2015; Jarpa, 2015).

Asimismo, Padilla, Douglas y López (2007 y 2011) señalan que en medios académicos suelen circular textos expositivos y argumentativos. Diversos autores han caracterizado el tipo discursivo de diferentes formas, por ejemplo, la exposición y la argumentación como dos polos de un continuum (Arnoux, di Stefano y Pereira, 2002) y como formas de organización discursiva predominantes (Padilla, Douglas y López, 2007 y 2011). Las dos vertientes poseen algunos puntos en común: En el caso de la exposición, «se centra en un saber construido en otro lado y socialmente legitimado, buscando informar y tendiendo a borrar las huellas subjetivas para marcar una distancia y objetividad» (Villalonga y Padilla, 2017, p. 518); y en el caso de la argumentación, «se buscar persuadir y el sujeto se manifiesta confrontando o no su opinión con la de otros, a fin de construir nuevos conceptos o posturas y, por ello, en este discurso aparecen múltiples voces» (Villalonga y Padilla, 2017, p. 518).

\subsection{Revisión de antecedentes}

Algunos estudios regionales y nacionales han abordado el análisis de lo que se lee, y las perspectivas de los docentes y de los alumnos acerca de esto (Bigi, Chacón y García, 2013; Carlino, 2005; Giudice, 2014; Giudice, Godoy y Moyano, 2016; Godoy y Giudice, 2014; Pérez y Rincón, 2013). Estos estudios dieron a conocer que en ciencias sociales los alumnos universitarios generalmente leen textos académicos derivados de textos científicos, por ejemplo, los materiales de cátedra, los manuales, los libros y los capítulos de libros (Bigi, Chacón y García, 2013; Carlino, 2003 y 2005; Giudice, 2014; Giudice, Godoy y Moyano, 2016; Godoy y Giudice, 2014; Pérez y Rincón, 2013). Además, indicaron que los estudiantes muchas veces leen fotocopias de los textos académicos que se encuentran fuera de la obra completa (Carlino, 2005; Giudice, Godoy y Moyano, 2016).

Asimismo, los estudios revisados evidenciaron que los estudiantes declaraban leer mayormente apuntes de clase propios, materiales elaborados por los profesores, guías de textos elaboradas por los profesores, páginas webs y blogs, capítulos de libros fotocopiados, y, en menor medida, artículos científicos, informes de investigación, libros completos, artículos de opinión y apuntes de clase tomados por otro alumno (Bigi, Chacón y García, 2013; Pérez y Rincón, 2013). Por su parte, los docentes señalaron que los estudiantes leen generalmente capítulos de libros y páginas web; en menor medida, artículos 
científicos, artículos de opinión, diccionarios especializados y libros, y, pocas veces, ponencias, informes de investigación, notas de enciclopedias, guías de estudio, artículos de opinión y libros completos (Bigi, Chacón y García, 2013 citado en Villalonga y Padilla, 2017, p. 525).

En nuestro país -Argentina-, Giudice (2014); Giudice, Godoy y Moyano (2016); y Godoy y Giudice (2014) buscaron conocer las prácticas de lectura que declaran propiciar los docentes universitarios de la carrera de Psicología. Nos detendremos en estos desarrollos que, aunque se centran en las perspectivas docentes sobre lo que se lee, nos han parecido relevantes, ya que están focalizados en la disciplina Psicología.

Uno de sus estudios indagó qué textos leen y las perspectivas de los docentes sobre el material de lectura de la carrera de Psicología. Entrevistaron a docentes de materias troncales de la carrera de Psicología de una universidad pública. Hallaron que los profesores daban, como material de lectura, manuales — dada la gran cantidad de materias que cursan lo cual imposibilitaba la lectura de fuentes primarias- y capítulos de libros elaborados por referentes en la disciplina. Casi ninguno complementaba la lectura de capítulos de libro con la transcripción de clases teóricas y proponía la lectura de trabajos de investigación. En casi todas las materias, se empleaban fotocopias - desprovistas generalmente de elementos que permitan contextuar lo que se lee-. En pocas materias, se leían artículos de especialidad y material digitalizado. En cuanto a los alumnos, solían trabajar solamente con la bibliografía obligatoria, dejando de lado la posibilidad de consultar otras fuentes vinculadas (Giudice, Godoy y Moyano, 2016).

En la misma dirección, Savio (2015) se propuso describir y analizar las representaciones sociales de estudiantes de una universidad pública para conocer, entre otras cosas, cómo conciben las prácticas lectoras académicas. Encuestó a alumnos al ingresar y al concluir su primer ańo de estudio en la universidad y encontró que, en general, tanto al inicio como al finalizar el año académico, un alto porcentaje indicaba que le gustaba leer $(79,5 \%)$ y un porcentaje mucho menor indicaba lo contrario (15,2\%). Muchos de ellos declararon que leen solamente cuando esta actividad les es solicitada.

Tanto en la primera como en la segunda encuesta, al indagar sobre el tipo de textos que leen los estudiantes, un número importante pone a la literatura en primer término $(52,4 \%$ y $41,9 \%)$. Sin embargo, los que declararon en la primera encuesta que leían textos periodísticos en segundo término (19\%) y textos relativos a diferentes campos del saber académico-científico en el tercero $(11,6 \%)$, en la siguiente encuesta, invirtieron esto (lectura de textos provenientes del ámbito académico-científico, el 21,7\% y del ámbito periodístico, el 15,1\%). 
(Savio, 2015). Vemos que, en este caso, las prácticas de lectura y de escritura aparecen como respuestas frente a solicitudes por parte del docente y que el ingreso en la universidad plantea cambios en la clase de textos que se leen.

Finalmente, retomamos las reflexiones de Carlino (2002, 2003, 2005), de De Araujo y Gomes Bezerra (2013) y de Padilla, Solórzano y Pacheco (2009), quienes han propuesto que los docentes debieron «considerar enseñar a los estudiantes a leer los textos académicos disciplinares, ya que esto permitiría a los nóveles lectores poder incluirse en la comunidad lectora académica y disciplinar» (Villalonga y Padilla, 2017, p. 519). La importancia de esto puede verse, por ejemplo, en los desarrollos de estudios nacionales que Estienne y Carlino (2004), Fernandez y Carlino (2013) y Padilla, Douglas y López (2007 y 2011) han señalado:

En carreras universitarias del área de las Ciencias Sociales, suelen leerse múltiples fuentes textuales académicas que pueden ser de tipo argumentativo o expositivo, los cuales se leen según las posturas de cátedras, y que algunos docentes no logran visualizar esto con claridad o esperan que los estudiantes hayan aprendido a leer en la escolaridad secundaria teniendo en cuenta estos aspectos (Villalonga y Padilla, 2017, p. 519).

Por su parte, Padilla et al. (2009) insisten en la relevancia de enseñar las competencias lectoras necesarias a los estudiantes universitarios para que puedan leer textos científicos de mayor complejidad identificando sus partes canónicas y comprendiéndolas.

Así, en este trabajo, nos proponemos analizar el material de lectura del primer año de la carrera de Psicología de una universidad estatal y describir las concepciones de los docentes y de los estudiantes en torno al mismo.

\section{Metodología}

En este trabajo, combinamos los enfoques cuantitativo y cualitativo de investigación (Hernández, Fernández y Baptista, 2006). Los docentes que participaron en nuestra investigación fueron divididos en dos grupos — de aquí en más G1 (grupo uno) y G2 (grupo dos)—en función de la antigüedad en sus cargos. En el G1, incluimos docentes que tenían más de 15 (quince) años de antigüedad en sus cargos y, en el G2, docentes que tenían menos de 15 (quince) ańos en sus cargos. Tomamos este criterio, ya que la antigüedad docente no se correspondía con ascensos en la carrera, pero sí con mayor experiencia en su práctica. El G1 estaba conformado por 4 (cuatro) sujetos de sexo femenino y el G2 por 5 (cinco) sujetos de sexo femenino y 2 (dos) de sexo masculino. En el G1, 1 (una) docente era profesora titular de cátedra, 2 (dos) 
eran profesoras adjuntas a cargo de cátedra y 1 (una) era jefe de trabajos prácticos. En el G2, 3 (tres) docentes eran jefes de trabajos prácticos, 3 (tres) eran auxiliares docentes de primera categoría y 1 (uno) había obtenido recientemente el cargo de profesor adjunto a cargo de una materia, siendo que antes se desempeñaba como jefe de trabajos prácticos en la misma.

Los estudiantes que participaron fueron divididos en tres grupos - G1' (grupo uno prima), G2' (grupo dos prima) y G3' (grupo tres prima) — en función de las calificaciones obtenidas en los primeros parciales de las materias. En el G1', incluimos a los estudiantes que habían obtenido notas altas (7/10 y más) en los primeros parciales de las materias; en el G2', los que habían obtenido calificaciones medias (4/10 y más); y, en el G3', los que tuvieron calificaciones bajas (3/10 y menos). La media de edades fue de 18 años.

- Instrumentos: Entrevistas en profundidad a docentes y a estudiantes, y material bibliográfico que se emplea en el primer año de la carrera.

- Entrevistas en profundidad a docentes: Basadas en un guion con temáticas a abordar y teniendo en cuenta los objetivos específicos de nuestra investigación. Entrevistamos a 11 (once) docentes del primer año de la carrera de seis asignaturas diferentes al comienzo de clases. La duración fue de entre 50 (cincuenta) y 60 (sesenta) minutos promedio.

- Entrevistas en profundidad a estudiantes: Basadas en un guion con temáticas a abordar y teniendo en cuenta los objetivos específicos de nuestra investigación. Entrevistamos a 12 (doce) estudiantes del primer año de la carrera al iniciarse el ciclo lectivo. La duración fue de 50 (cincuenta) minutos promedio.

- Corpus: Textos que corresponden al material bibliográfico de las nueve materias del primer ańo de la citada carrera. Tres de estas materias son anuales, cuatro son cuatrimestrales y dos son entre bi y trimestrales. El corpus estuvo compuesto por 320 (trescientos veinte) textos.

Analizamos los textos y las entrevistas teniendo en cuenta categorías ya propuestas por autores y categorías emergentes. Asimismo, de forma cuantitativa, apelamos a herramientas de estadística descriptiva (frecuencias y porcentajes) y nos apoyamos en el SPSS (Statistical Package for Social Sciences).

I) Clases de textos: clases de textos incluidos en el material bibliográfico de las materias. Esta categoría comprende las siguientes sub-categorías: 1) textos académicos derivados de textos científicos: Libros, capítulos de libros, materiales de cátedra, manuales (Carlino, 2005; Padilla, 2013) 
2) textos científicos: Artículos de revistas de investigación, tesis, ponencias presentadas en congresos, informes, proyectos de investigación (Carlino, 2005; Padilla, 2013).

II) Tipo discursivo predominante: esta categoría comprende sub-categorías:

1) predominantemente expositivo

2) predominantemente argumentativo

3) con predominio de argumentación cotidiana, (Padilla, Douglas y López, 2007 y 2011)

4) conversacionales (Villalonga y Padilla, 2017).

\section{Resultados}

\subsection{Clases de textos que leen los alumnos}

Como se ve en la tabla 1, predominaron los textos académicos derivados de textos científicos y, entre estos, los capítulos de libros y las fichas de cátedra. En este sentido, apreciamos que los alumnos leen, en mayor medida, capítulos de libros (64,9\%); en menor cantidad, fichas de cátedra (14,7\%), materiales de cátedra - como definiciones, imágenes y clasificaciones- (11\%), introducciones de libros (13\%), transcripciones de clases o conferencias (15\%); y casi nada, trabajos monográficos $(0,3 \%)$, ensayos $(0,7 \%)$ y artículos de divulgación $(0,7 \%)$.

Tabla 1: Estadísticos descriptivos para la clase de textos en el corpus general

\begin{tabular}{lcc}
\hline \multicolumn{1}{c}{ Clases de texto } & $\mathrm{F}$ & $\mathrm{P}$ \\
\hline Capítulo de libro & 204 & 63,8 \\
Ficha de cátedra & 47 & 14,7 \\
Artículo de divulgación & 2 &, 6 \\
Artículo científico & 9 & 2,8 \\
Transcripción de conferencia o clase & 15 & 4,7 \\
Trabajo científico en actas de encuentro & 12 & 3,8 \\
Introducción de libro & 14 & 4,4 \\
Material de cátedra (definiciones, clasificaciones, imágenes) & 11 & 3,4 \\
Ensayo & 2 &, 6 \\
Trabajo monográfico & 1 &, 3 \\
Libro & 2 &, 6 \\
Entrevista & 1 &, 3 \\
\hline Total & 320 & 100,0 \\
\hline
\end{tabular}

Fuente: Elaboración propia (Villalonga y Padilla, 2017, p. 521). 


\subsection{Perspectivas de docentes y estudiantes sobre qué se lee}

\subsubsection{Capitulos de libro, fichas de cátedra y fotocopias}

Tanto los docentes del G1 como los del G2 señalaron que los estudiantes leen prioritariamente capítulos de libro y fichas de cátedra. Además, en algunas materias, leían artículos de revistas de psicología —algunas científicas-. Solo los docentes del G1 indicaron la relevancia de contextuar el material de lectura. Algunos docentes habían señalado que los estudiantes accedían a fotocopias o cuadernillos y no a los textos originales.

E: Y... ¿usted ha visto con qué material trabajan?

D: Mira, hay cuadernillos circulando... Nosotros dejamos la selección de textos en la biblio porque hay pocos libros, para facilitar un poco las cosas...y hay capítulos de libros y fichas de cátedra básicamente (docente 8, G1).

E: ¿Qué clase de textos leen?

D: Hay capítulos de libros y dos artículos o tres de revistas de...como la de la Facultad, de revistas científicas, pero son cortos y simples... (docente 6, G 2).

$\mathrm{D}:$... y siempre vamos con una fuente primaria y una secundaria... Me importa mucho que sepan quién escribió el texto, por qué, en qué momento específico...que sepan si lo que leen es un capítulo de libro, o un artículo o una ficha de cátedra...Y bueno, hay que darles fotocopias porque no alcanzan los libros de la biblioteca (docente 2, G 1).

Por su parte, los estudiantes del G1'y del G2' indicaron leer capítulos -o partes de libros- y fichas de cátedra y, en igual medida, señalaron la cuantiosa cantidad a leer y cuan extensos resultan los textos. Reconocieron que lo que se lee son fotocopias de los capítulos de libros y acceden a los originales. Indicaron también que las fichas de cátedra planteaban de forma más sencilla lo que los capítulos desarrollan de manera más compleja.

E: ¿`Y qué tipo de textos son?

A: Mmmm...son capítulos de libros. Por eso son más largos...en Vital también vimos capítulos, pero esos son más fáciles. Hay muchas fichas de cátedra en esa materia. Como en la Integración, también había muchas fichas de cátedra (alumno 4, G 1').

E: Y decime, vos, ¿vos notás, ves diferencias entre los textos del colegio y los de aquí?

A: ¡Ufff! Sí, es un montón para leer, las fotocopias, son muy largas, no son dos tres hojitas de un manual, son partes enteras de libros, es un montón, pero son fotocopias, no son los libros de verdad (alumno 17, G 2'). 
E: ...Te dan partes de libros más largas que las que yo he leído en el cole...y está bueno, porque hay fichitas de cátedra que te ayudan con la lectura de los textos...porque te dicen más fácil las cosas que en los textos están en más difícil (alumno 16, grupo 2).

\subsubsection{Resúmenes y carpetas}

Los docentes del G1 y los del G2 reconocieron que los estudiantes leen carpetas o resúmenes hechos por terceros y que, en muchos casos, estos textos tendrían el mismo status que los incluidos en la bibliografía del programa. Además, señalaron que los estudiantes apelarían a este tipo de materiales de lectura porque son cortos y les permitirían aprobar los parciales.

D: Es una realidad, ellos o estudian algún resumen sin figuras de memoria o estudian de la carpeta bajada de internet sin figuras, que son tres hojitas...ese apuntencito es casi como parte de la biblio del programa (docente 9, G 2).

E: ¿Y qué leen los chicos?

D: En teoría, deberían leer el material que se sugiere desde la cátedra y en la práctica, bueno, tenés esas carpetas...que andan circulando...y entonces, el tema es que como esa carpeta que le pasaron es casi más importante que la biblio del programa...porque ni se preguntan si lo que está en esas carpetas está bien o mal (docente 5, G 1).

Solo los alumnos del G2' y del G3' señalaron que utilizan como material de estudio resúmenes y carpetas que no constituyen una elaboración personal. Respecto de quién ha elaborado la carpeta o el resumen, si bien los empelan para estudiar, no saben cuál era su procedencia. Además, la manera de evaluar cuan válidos y confiables resultaban se relacionaba con la capacidad de aprobar exámenes parciales con base en los mismos.

E: ¿Y vos sabés quién ha hecho esos resúmenes?

A: No, ni idea, la verdad que no, pero nos fue bien a todos los que estudiamos de ahí para el parcial, entonces tan mal no deben estar (alumno 11, G 3').

$\mathrm{E}:$ ¿Y vos sabés quién hace los resúmenes?

A: La verdad que no. Son como apuntes de gente que prepara alumnos, calculo que son confiables, porque pude zafar con esos (alumno 10, G 2')

\subsubsection{Cuadernillos y fotocopias}

Una cuestión que fue detectada por los estudiantes del G2' y del G3', e indicada por los docentes, es el hecho de que en la universidad se leen fotocopias. Sin embargo, a diferencia de los docentes, estos estudiantes declararon que 
muchas veces no podían precisar el origen de las fotocopias y, cuando lo hacían, se trataba de libros a los cuales no accedían. Cabe señalar que algunos de estos estudiantes no han mencionado la lectura de textos.

E: ¿Y qué leés aquí en la facultad?

A: Mmmm...fotocopias (se ríe)

E: Bien, pero fotocopias de qué

A: $Y$ de los apuntes que hay que estudiar

E: Claro, pero, de esas fotocopias, ¿les explicaron de dónde vienen?

A: Sí, de los libros, pero a los libros yo no los veo en vivo y en directo, porque está la fotocopia.

E: ¿Las fotocopias siempre son de libros?

A: Supongo, no sé, yo sé que está el cuadernillo con los apuntes y que de ahí hay que leer (alumno 13, G 2').

\subsection{Uso de diversas fuentes o textos originales de los autores vs textos que dicen en fácil lo que dicen otros textos}

Los docentes del G1 reconocieron que solicitan a los estudiantes la lectura de diversas fuentes para dar cuenta de un tema y, que estas fuentes suelen ser primarias y secundarias, indicando el valor de la fuente secundaria para la comprensión de la primaria.

D:... un tema no se ve desde un texto, se puede ver desde dos o más...y no es lo mismo lo que se lee en esta materia que tiene fuentes primarias que lo que se lee en otras materias que tienen fuentes secundarias...Entonces...en los autores clásicos, Marx, Weber, Durkheim, tenemos la lectura del cásico directamente y después tenemos un Ritzer que hace la síntesis del clásico con los conceptos centrales del pensamiento del autor y datos que permitan contextuar histórica y socialmente a ese autor (docente 2, G 1).

D: $Y$ aquí, en la universidad, se encuentran con fuentes primarias, extensas, y a veces con fuentes secundarias...en esta materia, que por los temas que trabajamos... en muchos casos, están las fuentes primarias, por decirte, textos originales de Freud, de Piaget, de Watson... ¿¿sí? Pero no termina ahí el asunto, porque para que un alumno de primer ańo pueda entender estos textos, la fuente secundaria es fundamental, indispensable (docente $3, \mathrm{G} \mathrm{1}$ ).

Si bien los tres grupos de estudiantes entrevistados no hablaron de fuentes textuales, los del G1' y los del G2' indicaron como característica de los textos que leen el hecho de que algunos son escritos por autores de renombre y otros 
son textos que explican de manera más sencilla lo planteado por los primeros. Además, identificaron que esta disposición del material de lectura se verifica principalmente en algunas materias. A diferencia de los estudiantes del G1' y del G2', los del G3' no consideraron que haya textos que mediaticen los planteos de otros textos.

A: Y Problemas es difícil, pero está bueno porque leés los textos originales de los autores importantes y también hay otros textos que te dicen en más fácil lo mismo (alumno 3, G 2').

E: $\mathrm{Y}$ vos, vos ¿̨notás diferencias entre los textos de las materias?

A: Sí, sí, como que Introducción o Problemas tienen esos textos...como se dice...este...eso de que si vos tenés a Weber, leés Weber, no alguien que resume lo que ha dicho Weber...pero en Introducción no tenés así y sí, porque bueno, en el cuadernillo están los autores, están los textos de los autores, pero no hay textos de otros que te resumen a lo que dicen los autores, no hay un texto que resuma lo de Piaget (alumno 16, G 3').

\subsection{Tipo discursivo predominante en los textos que leen los estudiantes}

En la tabla 2, puede observarse que en el material bibliográfico en general primaron los textos de predominio expositivo sobre los textos de predominio argumentativo.

Tabla 2: Estadísticos descriptivos para el tipo discursivo en el corpus en general

\begin{tabular}{lcc}
\hline \multicolumn{1}{c}{ Tipo discursivo } & $\mathrm{F}$ & $\mathrm{P}$ \\
\hline De predominio expositivo & 210 & 65,6 \\
De predominio argumentativo & 99 & 30,9 \\
De predominio narrativo & 1 & 3 \\
Con predominio de argumentación cotidiana & 9 & 2,8 \\
Conversacional & 1 &, 3 \\
\hline Total & 320 & 100,0 \\
\hline
\end{tabular}

Fuente: elaboración propia (Villalonga y Padilla, 2017, p. 521).

\subsection{Perspectivas de docentes y estudiantes sobre las clases de textos que se leen}

\subsubsection{Textos argumentativos y textos expositivos}

Solo los docentes del G1 plantearon distinciones entre textos que exponen

$\mathrm{y}$ textos que argumentan. A los primeros, los describieron como textos más 
sencillos, sin vueltas que plantean o definen cosas y, en algunos casos, los identificaron con las fuentes secundarias. A los segundos, los describieron como textos complicados, con idas y vueltas, que incluyen voces de varios autores, en los que el autor critica cosas y toma otras a su favor, y plantea conclusiones, en los que hay argumentos y contraargumentos o textos y contratextos. En algunos casos, los identificaron con las fuentes primarias.

D: ... hay textos que pueden que son más fáciles, son las fuentes secundarias, y ahí como que se presentan los temas de forma más accesible, más simple, para los alumnos...Y hay otros textos, más complicados...porque el autor incluye las voces de otros autores, y pude estar de acuerdo o no con esos otros autores que cita y así son nuestras fuentes primarias...son más difíciles para los alumnos (docente 3, G 1).

D: ...pensar los que es un texto argumentativo, un texto expositivo ¿sí? Y cómo se escribe y cómo se produce uno y otro, en que momento corresponde uno, en que momento corresponde otro...si pensás en un Freud que tiene tantas vueltas, primera tópica, segunda tópica, volver a la primera tópica, que la vuelta y las dos vueltas, y en eso, lo tópico ya no es tópico (se ríe), es un texto y hay contratexto, hay argumentos y contraargumentos ¿no? $Y$ eso no es lo mismo que explicar la neurona, la neurona, es la tal cosa y ya, sin vueltas (docente 1, G 1).

En igual medida, solamente dos estudiantes del G1' recibieron instrucción acerca de tipos discursivos y señalaron que en la bibliografía de las materias hay textos que exponen y textos que argumentan.

E: ¿Cómo son los textos que leés aquí en la facultad?

A: ...los textos que leés aquí son como argumentativos, bah, son argumentativos...y también hay de esos explican...son más directos, más fáciles también, porque no son textos que traigan lo que plantean otros tipos copados, cosas que van a favor o en contra de lo que trata de proponer el autor...son como más lineales y abundan

en detalles técnicos, como muy específicos de un área. Por ahí los textos de Psicofisiología...eso de que explican cosas con detalle, pero no tratan de convencerte de nada, porque se supone que si está leyendo eso no hace falta, tenés que comprar la verdura que te venden...

E: ¿¿Dónde has aprendido la diferencia entre textos que exponen y textos que argumentan?

A: En el cole (alumno 6, G 1'). 


\subsubsection{Textos complicados, enredados y textos vuelteros que nombran mucha gente}

Los docentes del G1 y del G2 describieron la presencia de textos enredados, complicados, con muchas idas y vueltas. Además, enunciaron que esta clase de textos se contraponen a otros que son cortos, sencillos y no muy enrevesados. Mientras que los del G1 consideraron que estos textos implicarían un desafío para los docentes y los alumnos, los del G2, indicaron que son muy complejos para los alumnos del primer ańo.

E: ¿Cuáles cree usted que serán los desafíos a los que se enfrenta un alumno de primer año para leer?

D: ...Los textos que se leen en algunas materias son enredados, complicados, enrevesados, no son fáciles de entender. Pero el desafío es para el docente y para el estudiante (docente 1, G 1).

E: Entonces, sintéticamente ¿en base a qué realizan la selección de textos?

D: Que sean cortos y sencillos...No me gustan esos textos muy enrevesados, porque son chicos de primer año...esos textos con muchas idas y vueltas, esos textos que el autor retoma algo que dice otro autor, y después lo niego o está favor, y después nombra a otro y lo mismo (docente 10, G 2).

$\mathrm{Al}$ igual que los docentes, los estudiantes de los tres grupos identificaron ciertas características del material de lectura que hacen a la complejidad de cómo están escritos, indicando la presencia de múltiples voces y la intención de convencer al lector.

E: ¿Y por qué te parecen difíciles?

A: Son largos, te nombran gente, teorías que no conocés, dan vueltas y te llenan de ejemplos, dicen una cosa, después la niegan, y después viene lo que dice el autor que, a todo esto, viene criticando a otros fulanos que ni conocés y que hablan de cosas que tampoco sabés, y cuando llega a una conclusión a veces no es tan cantada. En el cole nos enseñaron que eso es argumentar. Te marean, te despistan y tratan de convencerte o de engańarte... (alumno 3, G 2').

E: Claro, claro. Y entre las materias que estás cursando aquí ¿encontrás diferencias entre los textos?

A: ...Los de Introducción son largos y vuelteros con muchos autores que dicen muchas cosas, no está tan fácil, uno puede perderse en medio de esa maraña de ideas que van y que vienen (alumno 18, G 3'). 


\subsubsection{Textos sencillos, cortos y textos fáciles, entendibles}

Los docentes del G1 y del G2 propusieron que la selección bibliográfica incluye textos a los que caracterizan como cortos y sencillos. Los del G1 contrapusieron estos textos a otros que denominaron como largos y enredados, y señalaron que los primeros facilitan la lectura de los segundos.

E: Entonces, sintéticamente ¿̇en base a qué realizan la selección de textos?

D: Que sean cortos y que sean sencillos para los chicos, no muy enredados...Y a los chicos que recién entran, a la mayoría, les va a costar leer todo, nosotros tratamos de hacer una selección teniendo en cuenta que tan difíciles son los textos, pero seguramente que les va a costar... (docente 10, G 2')

En la misma dirección, los estudiantes de los tres grupos identificaron también ciertas características del material de lectura que hacen a cierta simplicidad en cómo están escritos. En contrapartida, dieron a conocer la presencia de otros textos que resultan entendibles, directos, claros, más fáciles.

E: Claro, claro. Y entre las materias que estás cursando aquí ¿encontrás diferencias entre los textos?

A: Los de Psicofisiología son así, sin vueltas, directos, más fáciles, muy detallados, con muchos detalles, eso sí, y largos. Los de Introducción son largos y vuelteros con muchos autores que dicen muchas cosas (alumno 8, G 1').

A: Hay textos que... que bueno te dicen las cosas así, de una, clarito como los de Psico y otros como Problemas o Introducción que te dicen las cosas enredadas porque hay muchos autores... (alumno 22, G 2').

A: ...Psico, son largos, pero como más directos, más de frente, sin tanto laberinto, más accesibles... (alumno 24, G 3’).

Los estudiantes del G2' y del G3' identificaron como un tipo de texto que leen las carpetas de resúmenes, las cuales resultan más accesibles o entendibles que los textos de la bibliografía.

E: ¿Vos creés que tenés dificultades para entender los textos de las materias?

A: Algunas, con esos largos y como enredados...con los otros, los directos, los de Psicofisiología o los de Vital...Pero bueno, como tengo carpetas que me pasaron por ahí de los textos que he llegado a leer se entiende más cuando uno tiene los resúmenes (alumno 9, grupo 2).

E: ¿Accesibles en qué sentido?

A: No son largos los apuntes, las fotocopias, y son de cosas que más menos se entienden, cómo más de la vida diaria, eso lo de Antropología, y la Integración, 
eran apuntes, de temas, de temas de las materias del primer año, pero como eran más cortos y más fáciles, más accesibles, entonces, se entienden bien cuando uno lee (alumno 5, grupo 3).

\section{Discusión}

Hasta aquí apreciamos que al igual que lo planteado en la literatura de especialidad (Bigi, Chacón y García, 2013; Carlino, 2003 y 2005; Giudice, 2014; Giudice, Godoy y Moyano, 2016; Godoy y Giudice, 2014; Pérez y Rincón, 2013; Savio, 2015) en esta carrera se leen textos académicos derivados de textos científicos y textos científicos, como los materiales de cátedra, los manuales, los capítulos de libros y los artículos de revistas.

Además, lo declarado por los docentes sobre las clases de textos que se leen, resulta consonante con el análisis del material bibliográfico — capítulos de libros, documentos de cátedra y artículos de revistas-. Esto, en parte, resulta afín a lo indicado por Bigi, Chacón y García (2013), quienes hallaron que los docentes declaraban que los estudiantes leían capítulos de libro y artículos científicos, entre otros textos. Una excepción la constituye el empleo de las carpetas y resúmenes que los docentes con más y con menos experiencia plantean como un hecho generalizado y que no ha sido señalado en la literatura revisada.

Los estudiantes con rendimiento medio y alto declararon leer partes de libro y materiales de cátedra, lo cual se sitúa en la misma dirección que lo indicado por los docentes y, en parte, por lo indicado en los estudios relvados (Bigi, Chacón y García, 2013; Pérez y Rincón, 2013; Savio, 2015). En cambio, los estudiantes que tuvieron un rendimiento medio y bajo se refieren al material bibliográfico, en términos de fotocopias de libros, sin poder diferenciar la clase de textos que este material incluye. Esto último, por una parte, se aparta de lo señalado por los docentes quienes indican que los alumnos leen en general capítulos de libros y documentos de cátedra y, por la otra, resulta coincidente en el punto de que los docentes reconocen la lectura de fotocopias del material bibliográfico. Asimismo, los estudiantes con rendimiento medio y bajo son los únicos que han declarado emplear resúmenes hechos por terceros y carpetas, lo cual no ha sido indicado ni por los docentes entrevistados ni en la literatura de especialidad relevada.

$\mathrm{Al}$ igual que lo planteado en los estudios nacionales relevados (Estienne y Carlino, 2004; Fernandez y Carlino, 2013; Padilla, Douglas y López, 2007 y 2011), en este caso, se aprecia el uso de múltiples fuentes textuales y que esto es explicitado por los docentes con mayor antigüedad y por estudiantes con 
un rendimiento alto y medio. Sin embargo, a diferencia de la literatura citada, notamos que los docentes reconocen el empleo de fuentes primarias y secundarias, y que los estudiantes también lo hacen. Resulta significativo que los docentes más nóveles no expliciten este aspecto y que los estudiantes con bajo rendimiento no comprendan la diferencia entre fuentes textuales.

Vemos cómo la diferencia en cuanto al tipo discursivo textual identificada al analizar el material bibliográfico también es notada tanto por los docentes como por los estudiantes. Hay docentes y estudiantes que poseen conocimientos previos en torno a los tipos discursivos textuales y logran identificarlos en el material de lectura. En este caso, se trata de los estudiantes que han obtenido calificaciones altas en sus primeros parciales y los docentes que poseen más ańos de experiencia. Además, aunque hay docentes y estudiantes que parecen no tener este tipo de conocimientos previos, logran diferenciar los textos según características que hacen a cómo están escritos. En este sentido, creemos que podrían diferenciar, aunque sin llegar a conceptualizarlos, los tipos discursivos (Arnoux, di Stefano y Pereira, 2002; Padilla, Douglas y López, 2007 y 2011).

La descripción sobre los textos llamados fáciles, directos, sencillos se ajustaría en parte a lo que se conceptualiza como textos predominantemente expositivos, sobre todo en lo referido a la función informativa y a la objetividad. La descripción de los textos llamados difíciles, que nombran mucha gente y que incluyen diversas opiniones, enredados, se relaciona con lo conceptualizado como textos predominantemente argumentativos (Arnoux, di Stefano y Pereira, 2002; Padilla, Douglas y López, 2007 y 2011) en lo referido al juego de planteos que pueden confrontarse o no con una opinión para construir nuevos conceptos o posturas (Arnoux, di Stefano y Pereira, 2002; Padilla, Douglas y López, 2007 y 2011).

\section{Conclusiones}

En este trabajo, hemos abordado el material de lectura del primer año de la carrera de Psicología, y las perspectivas de los docentes y de los estudiantes en torno al mismo. Hemos encontrado que los docentes declaran que en el material de lectura priman los textos académicos derivados de textos científicos, lo cual puede constatarse en el material en sí mismo. Entre estos textos hemos hallado que priman los expositivos sobre los argumentativos y, aunque los docentes más experimentados logran reconocer el tipo discursivo, los que tienen menor experiencia notan diferencias sin poder precisarlo a nivel conceptual. Mientras que los estudiantes con mejor rendimiento logran reconocer 
las clases de textos y los tipos discursivos, los que tienen menor rendimiento se refieren a los textos como fotocopias y notan diferencias en cuanto a cómo están escritos sin poder conceptualizarlas.

Esto nos lleva a preguntarnos acerca de la brecha entre la formación lectora del nivel secundario, y lo que se exige y se puede ofrecer en la universidad. Por un lado, nos encontramos con estudiantes que parecen haber recibido formación sobre clases textuales y tipos discursivos en la escolaridad secundaria y que poseen un buen rendimiento académico, y con docentes que poseen conocimientos al respecto. Por otro lado, hay docentes y estudiantes que no han tenido tan buen rendimiento, que poseen conocimientos sobre los tipos discursivos basados en observaciones de orden práctico y, hay estudiantes que se refieren a los textos como fotocopias sin poder indicar la clase textual. Ante este panorama, aquellos estudiantes que han recibido instrucción especializada durante la escolaridad secundaria contarían con más herramientas para aprehender la cultura lectora académica.

Sin embargo, el hecho de que haya profesores que no posean conocimientos explícitos sobre clases textuales y tipos discursivos nos lleva a preguntarnos en qué condiciones podrán enseñar esto en sus aulas a los estudiantes. Creemos que las generaciones más antiguas de docentes podrían realizar la selección del material de estudio teniendo esto en cuenta y que los más nóveles no reconocerían estos aspectos como inherentes a la lectura académica. Siguiendo a Padilla et al. (2009), creemos necesaria la enseñanza de las herramientas inherentes a los discursos científicos disciplinares y, en este caso, no solo a los estudiantes sino también a los docentes más nóveles.

Por último, es importante señalar que en los siguientes estudios pueden abordarse algunos interrogantes que se desprenden de este (Villalonga y Padilla, 2017, p. 530):

- «¿Hay distancias entre los modos de lectura exigidos por los profesores en la universidad y los que los alumnos han construido en la secundaria?»

- ¿Cómo inciden las perspectivas sobre la lectura en las prácticas de enseñanza y de aprendizaje?

- ¿Hay posibilidades de ocuparse de la lectura en las aulas universitarias?

- ¿Qué tipo de ayudas pedagógicas proporcionan los docentes?

- ¿Qué tipo de ayuda esperan recibir los alumnos? 


\section{REFERENCIAS BIBLIOGRÁFICAS}

Arnoux, E., di Stefano, M. y Pereira, M. C. (2002). La lectura y la escritura en la universidad. Buenos Aires: Eudeba.

Barton, D., Hamilton, M. y Ivanic, R. (2000). Situated Literacies. Reading and writing in context. Londres: Routledge. Taylor \& Francis Group.

Barton, D. y Tusting, K. (2005). Beyond Communities of Practice. Language, Power and Social Contexts. Nueva York: Cambridge University Press. https://doi. org/10.1017/CBO9780511610554

Bigi, E., Chacón, E. y García, M. (2013). ¿Cuáles textos académicos leen los estudiantes universitarios en educación? Legenda, 17(17), 127-145.

Blommaert, J., Street, B., Turner, J. y Scott, M. (2007). Academic literacies -what have we achieved and where to from here? Journal of Applied Linguistics, 4(1), 137-148. https://doi.org/10.1558/japl.v4i1.137

Bolívar, A. y Parodi, G. (2015). Academic and professional discourse. En M. Lacorte (ed.), The Routledge Handbook of Hispanic Applied Linguistics (pp. 459-476). Nueva York: Routledge.

Carlino, P. (2002). ¿Quién debe enseñar a leer y escribir en la universidad? Lectura $y$ Vida, 23(1), 1-10.

Carlino, P. (2003). Alfabetización académica: un cambio necesario, algunas alternativas posibles. Educere, Investigación, 20, 409-420.

Carlino, P. (2005). Escribir, leer y aprender en la universidad. Una introducción a la alfabetización académica. Buenos Aires: Fondo de Cultura Económica.

Cassany, D. (2005). Literacidad crítica: leer y escribir la ideología. En Taller en el IX Simposio Internacional de la Sociedad Española de Didáctica de la Lengua y la Literatura. Barcelona, junio de 2004.

Chanock, K. (2011). A historical literature review of Australian publications in the field of Academic Language and Learning in the 1980s: Themes, schemes, and schisms: Part Two. Journal of Academic Language and Learning, 5(1), 59-A87.

De Araujo, C. y Gomes Bezerra, B. (2013). Letramentos Académicos: Leitura e escritura de gêneros acadêmicos no primeiro ano do curso de Letras. Diálogos. Revista de Estudos Culturais e da Contemporaneidades, 9, 5-37. https://doi.org/10.13115/2236-1499.2013v1n9p5

Estienne, V. y Carlino, P. (2004). Leer en la universidad: enseñar y aprender una nueva cultura. Uni/pluiversidad, 3(4), 1-13.

Fernandez, G. M. E. y Carlino, P. (2013). ¿En qué se diferencian las prácticas de lectura y de escritura en la universidad y en la escuela secundaria? Lectura y Vida, 31(3), 6-19. 
Giudice, J. (2014). La adquisición del lenguaje disciplinar y académico en el inicio de los estudios universitarios: análisis de una experiencia educativa. En Libro de resúmenes del Congreso Nacional Cátedra Unesco para el mejoramiento de la calidad y equidad de la educación en América Latina, con base en la lectura y la escritura (pp. 24-25). Rosario.

Giudice, J., Godoy, M. y Moyano, E. I. (2016). Prácticas de lectura y escritura en el marco de la enseñanza de la psicología: avances de una investigación interdisciplinaria. Revista Mexicana de Investigación Educativa, 69(21), 501-520.

Godoy, M. y Giudice, J. (2014). Problemática de los docentes en relación a las prácticas de lectura y escritura de sus alumnos universitarios y una modalidad de abordaje desde la gestión. En Libro de resúmenes del Congreso Nacional Cátedra Unesco para el mejoramiento de la calidad y equidad de la educación en América Latina, con base en la lectura y la escritura (p. 25). Rosario.

Hernández, R., Fernández, C. y Baptista, P. (2006). Metodología de la Investigación. México: McGraw and Hill. Interamericana.

Jarpa, M. (2015). Escritura en las disciplinas: géneros académicos evaluativos en un programa de posgrado de Biotecnología. En G. Parodi y G. Burdiles (eds.), Leer y escribir en contextos académicos y profesionales: géneros, corpus y métodos (pp. 221-255). Santiago de Chile: Ariel

Lea, M. (2005). Communities of practice in higher education. Useful heuristic or educational model? En D. Barton y K. Tusting (eds.), Beyond communities of practice (pp. 180-197). Cambridge: Cambridge University Press. https://doi.org/10.1017/CBO9780511610554.010

Lillis, T. y Scott, M. (2007). Defining academic literacies research: issues of epistemology, ideology and strategy. Journal of Applied Linguistics, 4, 5-32. https://doi.org/10.1558/japl.v4i1.5

Padilla, C. (2013). Ficha de clasificación de discursos. Material de uso interno. Taller de comprensión y producción de textos, Carrera de Letras, Facultad de Filosofía y Letras. Universidad Nacional de Tucumán.

Padilla, C., Douglas, S. y López, E. (2007). Yo expongo. Taller de prácticas de comprensión y producción de textos expositivos. Córdoba: Comunicarte.

Padilla, C., Douglas, S. y López, E. (2011). Yo argumento. Taller de prácticas de comprensión y producción de textos argumentativos. Córdoba: Comunicarte.

Padilla, M.A., Solórzano, W. y Pacheco, V. (2009). The effects of text analysis on drafting and justifying research questions. EJREP, 7(1), 77-102.

Parodi, G. (2008). Géneros académicos y géneros profesionales. Accesos discursivos para saber y hacer. Valparaíso, Chile: Ediciones Universitarias de Valparaíso. 
Parodi, G. (2015). Leer a través de las disciplinas en la universidad: ¿Qué géneros permiten acceder al conocimiento en la formación doctoral? En G. Parodi y G. Burdiles (eds.), Leer y escribir en contextos académicos y profesionales: géneros, corpus y métodos (pp. 31-66). Santiago de Chile: Ariel

Pérez, M. y Rincon, G. (2013). Para qué se lee y se escribe en la universidad. Bogotá: Pontificia Universidad Javeriana.

Savio, K. (2015). La lectura y la escritura: un estudio sobre representaciones sociales de estudiantes universitarios. Revista Actualidades Investigativas en Educación, 15(2), 7-26. https://doi.org/10.15517/aie.v15i2.18959

Villalonga, M. y Padilla, C. (2017). ¿Qué textos leen en primer año los estudiantes de Psicología? Educacao e Pesquisa, 43(2), 515-533. https://doi. org/10.1590/s1517-9702201610150998 